\title{
Validation of the Portuguese version of the RDC/TMD Axis II questionnaire
}

\section{Validação do questionário RDC/TMD Eixo II em português}

\author{
Luciana Barbosa Sousa de Lucena* \\ Maurício Kosminsky** \\ Lino João da Costa*** \\ Paulo Sávio Angeiras de Góes****
}

\begin{abstract}
The present paper aimed at evaluating the validity of the Portuguese version of the Research Diagnostic Criteria for Temporomandibular Disorders (RDC/TMD) Axis II Questionnaire. The sample was comprised of 155 patients with signs and symptoms of Temporomandibular Disorders (TMD), evaluated at the Orofacial Pain Control Center, School of Dentistry, University of Pernambuco, Brazil, between July 2003 and February 2004. Data collection was performed with the following tools: the RDC/TMD Axis I (clinical evaluation and TMD classification), and Axis II (psychosocial evaluation), as well as specific questionnaires for evaluation of Oral Health Related Quality of Life, namely, Oral Impacts on Daily Performances and the Oral Health Impact Profile-14, considered to be gold standard criteria. Validity evaluation consisted of internal consistency evaluation by the Cronbach alfa reliability test, reliability and reproducibility estimated by the Kappa test and the Spearman's correlation, and concurring validation through Spearman's correlation. The Portuguese version of the RDC/TMD Axis II questionnaire was considered consistent (Cronbach alfa $=0.72$ ), reproducible (Kappa values from 0.73 to $0.91, \mathrm{p}<0.01$ ), and valid $(\mathrm{p}<0.01)$. It was concluded that this version showed valid and reproducible results for the Brazilian population, thus paving the way for including Brazil in transcultural epidemiological studies on TMD.
\end{abstract}

DESCRIPTORS: Temporomandibular joint disorders; Validation studies; Sickness impact profile.

RESUMO: O presente trabalho objetivou avaliar a validade da versão em português do questionário Eixo II dos Critérios Diagnósticos de Pesquisa em Disfunção Temporomandibular (RDC/TMD). A amostra foi composta por 155 pacientes com sinais e sintomas de disfunção temporomandibular (DTM) atendidos no Centro de Controle da Dor Orofacial da Faculdade de Odontologia da Universidade de Pernambuco, Brasil, no período de julho de 2003 a fevereiro de 2004. Para a coleta de dados foram utilizados os seguintes instrumentos: RDC/TMD Eixo I, para avaliação clínica e classificação da DTM, Eixo II, para avaliação psicossocial, e os questionários específicos para avaliação da qualidade de vida relacionada à saúde bucal: Impacto da Saúde Bucal nas Atividades Diárias e Perfil do Impacto na Saúde Bucal-14, considerados padrões-ouro. A validação consistiu na avaliação da consistência interna pelo teste de confiabilidade alfa Cronbach, confiabilidade e reprodutibilidade estimadas pela estatística Kappa e correlação de Spearman e validação concorrente, mediante correlação de Spearman. A versão em português do questionário Eixo II do RDC/TMD foi considerada consistente $(\alpha$ Cronbach $=0,72$ ), reprodutivel (valores de Kappa entre 0,73 e $0,91 ; \mathrm{p}<0,01)$ e válida $(\mathrm{p}<0,01)$. Conclui-se que o instrumento em estudo mostrou-se reprodutível e válido para a população brasileira, possibilitando, assim, a inclusão do Brasil em estudos epidemiológicos transculturais em disfunção temporomandibular.

DESCRITORES: Transtornos da articulação temporomandibular; Estudos de validação; Perfil de impacto da doença.

\section{INTRODUCTION}

Currently, several protocols are available in the literature for diagnosis and classification as well as clinical treatment and research strategies. However, most methods only emphasize findings obtained during clinical examination, requiring the inclusion of other instruments for evaluating psychosocial factors. In addition, the majority of instruments and questionnaires were created originally for English language speakers and their use for populations of non-English speakers could bias the results. This is because the translation process itself, without a cultural context, does not guarantee its success due to peculiarities in language and cultural behaviors. ${ }^{9}$

Therefore, we cannot expect to have equivalent results from the use of an instrument without submitting it to predefined rules established in the

* PhD, Professor, Discipline of Topographic Anatomy; ***PhD, Professor, Discipline of Stomatology - Federal University of Paraíba.

** PhD, Professor, Discipline of Orofacial Pain and Temporomandibular Disorders; ****PhD, Professor, Discipline of Public Health School of Dentistry, University of Pernambuco. 
Lucena LBS, Kosminsky M, Costa LJ, Góes PSA. Validation of the Portuguese version of the RDC/TMD Axis II Questionnaire. Braz Oral Res 2006;20(4):312-7.

literature for translation, back-translation, face validation, cultural adaptation and psychometric properties equivalence measurement. In addition, reproducibility and validity must be tested..$^{2,8,9,11}$

For this purpose, Dworkin, LeResche ${ }^{4}$ (1992) developed a set of diagnostic tools for TMD, namely the Research Diagnostic Criteria for Temporomandibular Disorders (RDC/TMD). These represent a multiaxial approach, evaluating clinical aspects of TMD (Axis I), as well as psychological and psychosocial factors (Axis II). The RDC/TMD are an accepted and validated diagnostic tool for epidemiological and clinical research on TMD. ${ }^{11,14,17}$

The term temporomandibular disorder (TMD) covers a group of clinical disturbances affecting the masticatory muscles, the temporomandibular joint (TMJ) or both. ${ }^{12}$ Its clinical course varies, comprising concurrent or isolated muscular and articular pain, limited or asymmetric mandibular movements, as well as joint sounds. ${ }^{4}$ TMDs have multifactorial etiology, including trauma, bruxism, joint hypermobility, and appear to be strongly influenced by psychosocial factors. ${ }^{4}$

Epidemiological studies on TMDs have shown controversial results regarding prevalence and incidence. These findings could be attributed to different diagnostic criteria. Thus, a standardized methodology is necessary when comparing studies related to this disease.

Initially, the RDC/TMD were developed for the English language. Their translation and validation have been made for various non-English speaking populations, allowing the application of transcultural clinical studies. ${ }^{5}$

The translation of the RDC/TMD into Portuguese was conducted by Pereira et al. ${ }^{15}$ (2002), by means of the International RDC/TMD English-Portuguese Project. Furthermore, Kosminsky et al. ${ }^{11}$ (2004) performed the face validation and cultural adaptation, resulting in the Portuguese version of the RDC/TMD Axis II. However, this version has not yet been submitted to a validation process, which prevents its use. The aim of this study was to evaluate the validity of the Portuguese version of the RDC/TMD Axis II.

\section{MATERIAL AND METHODS}

The study population consisted of male and female patients with orofacial pain from different social backgrounds seeking treatment at the Orofacial
Pain Control Center, School of Dentistry, University of Pernambuco, Brazil, from July 2003 to February 2004. The sample comprised 155 individuals with ages ranging from 18 to 65 years $($ mean $=37.3$ years), $89 \%$ of whom were females and $11 \%$ males. All patients had TMD. The study inclusion criteria were the following: no previous history of TMD treatment, positive diagnosis of TMD, using the Fonseca et al. ${ }^{6}$ (1994) Simplified Anamnestic Index (SAI), and inclusion in one of the three TMD groups according to the RDC/TMD Axis I questionnaire established by Dworkin, LeResche ${ }^{4}$ (1992).

\section{Patient history/data collection}

The following questionnaires were used:

a) Simplified Anamnestic Index: ${ }^{6}$ the SAI verified the presence of signs and symptoms of TMD providing a prompt diagnosis. All patients were classified as having TMD.

b) RDC/TMD Axis II Questionnaire (Portuguese version) $)^{*}:{ }^{11}$ this consisted of 31 items, divided into socio-demographic, socio-economic, psychological (depression subscales and nonspecific physical symptoms - pain items included and pain items excluded), psychosocial (graded chronic pain severity - pain intensity and disability); patient-related signs and symptoms and the limitation scale on mandibular function (limitations related to mandibular functioning).

c) Oral Impacts on Daily Performances (OIDP) and the Oral Health Impact Profile (OHIP-14): to evaluate oral health-related quality of life, both questionnaires were used. The OIDP consisted of nine questions related to how the mouth and teeth disrupt daily activities. The OHIP-14 comprised 14 questions for measuring the perception of the impact of orofacial pain on well-being related to TMD.

\section{Clinical data collection}

Items regarding clinical variables (Axis I) were filled out according to their order on the RDC/TMD Axis I Examination Form, whose findings correspond to the 10 items of the evaluation protocol for orofacial anatomic elements.

\section{Validation process}

The validation process consisted of:

a) Internal consistency (validity): this was esti-

\footnotetext{
* Available access: $h t t p: / / w w w . c c s . u f p b . b r / m o r f o l o g i a / q u e s t i o n a r i o r d c t m d . p d f$.
} 
Lucena LBS, Kosminsky M, Costa LJ, Góes PSA. Validation of the Portuguese version of the RDC/TMD Axis II Questionnaire. Braz Oral Res 2006;20(4):312-7.

mated from the limitation scale on mandibular function, part of the RDC/TMD Axis II Questionnaire, evaluating whether the 12 items had the same conceptual domain and correlated with one another. The degree of correlation was tested between the several domains of the RDC/TMD Axis II, considering the three subscales for psychological factors, graded chronic pain severity and limitation scale on mandibular function.

b) Reliability and reproducibility: this consisted of a test-retest study of the RDC/TMD Axis I and II Questionnaires, applied to 45 participants randomly selected two weeks after the first test by the same clinician, none of whom had received any previous treatment for any associated co-morbidity or pharmacological or physical therapy for TMD.

c) Concurrent validity: the Portuguese version of the RDC/TMD Axis II, as well as the gold standard Oral Impacts on Daily Performances and the Oral Health Impact Profile-14 forms were tested in 155 sample individuals. The concurrent validity (convergent type) was determined by correlating results obtained from domains of the limitation scale on mandibular function (RDC/TMD Axis II) and Oral Impacts on Daily Performances and the Oral Health Impact Profile-14 scores. The assigned TMD scores from the Simplified Anamnestic Index ${ }^{6}$ were compared with scores from the graded chronic pain severity (RDC/TMD Axis II).
Divergent validity was demonstrated by correlating results obtained from the psychological subscale domains (RDC/TMD Axis II), the Oral Impacts on Daily Performances and the Oral Health Impact Profile-14 scores, testing their psychometric properties. ${ }^{1,10,16}$

\section{Statistical analysis}

The data obtained were organized and processed with the aid of a statistical software program (Statistical Package for the Social Sciences - SPSS for Windows, version 10) for descriptive and inferential analysis. The level of statistical significance used was $5 \%$. Internal consistency was estimated by the Cronbach alfa Test and considered satisfactory with values above $0.5 .^{7}$ The test-retest reliability was estimated by the Cohen Kappa scale ${ }^{3}$ and Spearman's rank correlation test $(\mu>.05) .{ }^{3,16}$ Concurrent, convergent and divergent validity were evaluated by Spearman's rank correlation test. ${ }^{3,16}$

\section{RESULTS Internal consistency}

The evaluation of the internal consistency on limitation related to mandibular functioning as a RDC/TMD Axis II criterion identified 12 items that correlated with one another and represented the whole scale (alpha $=0.72)$ and standardized item alpha 0.73 , as shown in Table 1 . Alpha values did not increase by removal of any tested item.

TABLE 1 - Internal consistency of limitations related to mandibular functioning values of the RDC/TMD Axis II, evaluated by test-retest in 45 individuals.

\begin{tabular}{|c|c|c|c|c|c|}
\hline \multirow{2}{*}{$\begin{array}{l}\text { Limitation related to mandibular } \\
\text { functioning RDC/TMD AXIS II }\end{array}$} & \multicolumn{5}{|c|}{ Statistical parameters if item deleted } \\
\hline & Mean & Variance & $\begin{array}{c}\text { Corrected Item-Total } \\
\text { Correlation }\end{array}$ & $\begin{array}{l}\text { Square Multiple } \\
\text { Correlation }\end{array}$ & $\begin{array}{c}\text { Alpha if Item } \\
\text { Deleted }\end{array}$ \\
\hline Eating hard foods & 5.34 & 5.67 & 0.15 & 0.41 & 0.72 \\
\hline Exercising & 6.09 & 5.20 & 0.22 & 0.40 & 0.72 \\
\hline Yawning & 5.43 & 5.18 & 0.36 & 0.51 & 0.70 \\
\hline Smiling/laughing & 5.52 & 4.91 & 0.40 & 0.50 & 0.70 \\
\hline Talking & 5.68 & 4.78 & 0.37 & 0.39 & 0.70 \\
\hline Swallowing & 5.91 & 4.74 & 0.38 & 0.37 & 0.70 \\
\hline
\end{tabular}

Alpha $(\alpha)=0.72 ;$ standardized item alpha $(\alpha)=0.73$. 
Lucena LBS, Kosminsky M, Costa LJ, Góes PSA. Validation of the Portuguese version of the RDC/TMD Axis II Questionnaire. Braz Oral Res 2006;20(4):312-7.

TABLE 2 - Correlation between scales of the RDC/TMD Axis II.

\begin{tabular}{|c|c|c|c|c|c|}
\hline & \multicolumn{5}{|c|}{ "RDC/TMD AXIS II scales } \\
\hline & $\begin{array}{l}\text { Pain intensity } \\
\text { and disability }\end{array}$ & Depression & $\begin{array}{c}\text { Nonspecific } \\
\text { physical } \\
\text { symptoms } \\
\text { - pain items } \\
\text { included }\end{array}$ & $\begin{array}{l}\text { Nonspecific } \\
\text { physical } \\
\text { symptoms } \\
\text { - pain items } \\
\text { excluded }\end{array}$ & $\begin{array}{l}\text { Limitations } \\
\text { related to } \\
\text { mandibular } \\
\text { functioning }\end{array}$ \\
\hline Pain intensity and disability & 1.000 & - & - & - & - \\
\hline Depression & $\begin{array}{l}\mu=0.314 \\
p<0.001\end{array}$ & 1.000 & - & - & - \\
\hline $\begin{array}{l}\text { Nonspecific physical symptoms } \\
\text { - pain items included }\end{array}$ & $\begin{array}{l}\mu=0.328 \\
p<0.001\end{array}$ & $\begin{array}{l}\mu=0.708 \\
p<0.001\end{array}$ & 1.000 & - & - \\
\hline $\begin{array}{l}\text { Nonspecific physical symptoms } \\
\text { - pain items excluded }\end{array}$ & $\begin{array}{l}\mu=0.236 \\
p=0.003\end{array}$ & $\begin{array}{l}\mu=0.724 \\
p<0.001\end{array}$ & $\begin{array}{l}\mu=0.850 \\
p<0.001\end{array}$ & 1.000 & - \\
\hline $\begin{array}{l}\text { Limitations related to } \\
\text { mandibular functioning }\end{array}$ & $\begin{array}{l}\mu=0.414 \\
p<0.001\end{array}$ & $\begin{array}{l}\mu=0.230 \\
p=0.004\end{array}$ & $\begin{array}{l}\mu=0.294 \\
p<0.001\end{array}$ & $\begin{array}{l}\mu=0.267 \\
p=0.001\end{array}$ & 1.000 \\
\hline
\end{tabular}

Significant correlation at $P=0.01$.

TABLE 3 - Reliability and reproducibility of established diagnostic procedures in the RDC/TMD Axis I and II, evaluated by test-retest of 45 patients.

\begin{tabular}{|c|c|c|c|}
\hline \multirow{2}{*}{\multicolumn{2}{|c|}{ Diagnosis from the RDC/TMD }} & Statistical tests & Interpretation \\
\hline & & Kappa Value & Kappa \\
\hline \multirow{3}{*}{$\vec{a}$} & Group I (muscle disorders) & 0.73 & good agreement \\
\hline & Group II (disk displacements) & 0.91 & very good agreement \\
\hline & Group III (other joint conditions) & 0.78 & good agreement \\
\hline & & Spearman's Correlation $(\mu)$ & P Value \\
\hline \multirow{4}{*}{$\begin{array}{l}\boxminus \\
\cdot \frac{a}{4} \\
\frac{x}{4}\end{array}$} & Pain intensity and disability & 0.764 & $<0.01$ \\
\hline & Depression & 0.821 & $<0.01$ \\
\hline & Nonspecific physical symptoms, pain items included & 0.727 & $<0.01$ \\
\hline & Nonspecific physical symptoms, pain items excluded & 0.798 & $<0.01$ \\
\hline
\end{tabular}

The degree of correlation between the different domains of the RDC/TMD Axis II was obtained by considering the three subscales for psychological factors, the graded chronic pain severity and the limitation scale on mandibular functioning (Table 2). The Spearman scores were higher $(\mu \geq 0.7)$ for the three subscales regarding psychological domain, with a statistically significant correlation $(P<0.001)$. Lower scores $(\mu \leq 0.2)$ were obtained for scales with a poor correlation with one another; this result could be interpreted as applying also to other domains, such as the limitation scale on mandibular functioning (physical) and the psychological factor scales. Correlation values between the psychosocial and psychological domains were $\mu \leq 0.3$. Correlation values between the physical and psychosocial domains were $\mu=0.4$; however, this correlation is weak to moderate, indicating that, although these domains are part of the proposed domains measured by the scale, they add little to this study. ${ }^{1,10,16}$

\section{Evaluation of reliability and reproducibility}

Comparing information obtained from 45 patients (test-retest study), a diagnostic agreement was statistically significant in Axis I and II, as shown in Table 3.

\section{Concurrent validity}

According to Table 4, scores from the Oral Impacts on Daily Performances and the Oral Health Impact Profile-14 produced a greater degree of correlation with the limitation scale on mandibular functioning $(\mu \geq 0.5)$, signifying convergent validity, i.e., a positive correlation between limitation scale 
Lucena LBS, Kosminsky M, Costa LJ, Góes PSA. Validation of the Portuguese version of the RDC/TMD Axis II Questionnaire. Braz Oral Res 2006;20(4):312-7.

TABLE 4 - Spearman's rank correlation coefficients among items evaluated by the RDC/TMD Axis II, OIDP and OHIP scores.

\begin{tabular}{l|c|c|c|c}
\hline \hline \multirow{2}{*}{\multicolumn{1}{c}{ Items evaluated by the RDC/TMD AXIS II }} & \multicolumn{3}{|c}{ Correlation between scales } \\
\cline { 2 - 5 } & \multicolumn{2}{|c}{ OIDP } & \multicolumn{3}{c}{ OHIP } \\
\cline { 2 - 5 } & Spearman & P Value & Spearman & P Value \\
\hline Limitations related to mandibular functioning & 0.602 & $<0.01$ & 0.598 & $<0.01$ \\
\hline Depression & 0.306 & $<0.01$ & 0.349 & $<0.01$ \\
\hline Nonspecific physical symptoms - pain items included & 0.310 & $<0.01$ & 0.336 & $<0.01$ \\
\hline Nonspecific physical symptoms - pain items excluded & 0.258 & $<0.01$ & 0.261 & $<0.01$ \\
\hline \hline
\end{tabular}

on mandibular functioning and the Oral Impacts on Daily Performances and the Oral Health Impact Profile-14, measuring the same dimension. ${ }^{1,10,16}$ Low correlation values were obtained for the Oral Impacts on Daily Performances and the Oral Health Impact Profile-14 with the other items, such as psychological factor subscales $(\mu \leq 0.3)$, signifying a divergent validity and presenting a different psychometric capacity. ${ }^{1,10,16}$ Convergent validity was demonstrated by comparing the Simplified Anamnestic Index ${ }^{6}$ with the graded chronic pain scale, this comparison being statistically significant $(\mu=0.5, P<0.01)$.

\section{DISCUSSION}

The present study makes an important contribution to further research in the TMD area by validating the Portuguese version of the RDC/TMD Axis II Questionnaire. This instrument will allow the standardization of TMD diagnosis and the collection of psychosocial data on the Brazilian population, with a view to conducting transcultural epidemiologic studies on TMD.

The methodology used in this study judiciously follows the methodology already described in the literature, in accordance with similar criteria established by Ciconelli et al. ${ }^{2}$ (1999), Dworkin et al. ${ }^{5}$ (2002), Góes ${ }^{8}$ (2001), Guillemin et al. ${ }^{9}$ (1993) and Mota Falcão et al. ${ }^{13}$ (2003). The methodological norms found in the literature related to transcultural adaptation of research questionnaires should not be restricted only to translation, but should also include the back-translation, face validation, cultural adaptation and validity. ${ }^{9}$ The failure to perform any of these stages may lead to errors in the idiomatic, semantic, cultural and conceptual equivalences of the instrument. ${ }^{9}$

Each society has its own characteristics that reflect the culture of a country, as well as what differentiates it from others. Likewise, health prob- lems are expressed in different ways from one culture to another. Thus, when it is intended to apply an instrument of health-related data collection it should follow the methodology proposed in the literature and result in an instrument with clear, simple language and with equivalence with regard to cultural concepts. ${ }^{2}$ In epidemiology, the validity of data collection is one of the most important aspects in the consistency of the study.

The instrument used in this study was composed of several scales with different psychometric capacities. However, for the limitation scale on mandibular functioning, based on a list of commonly used items in TMD clinical research, reliability and validity have not been evaluated yet. ${ }^{4}$

The internal consistency of a group of items can be evaluated by the Cronbach alpha test, where it is necessary to know whether these items could result in a measurement scale with the same domain. . 10,16 This test indicates the degree of correlation of an item with a scale and an item with itself. To be considered relevant, the degree of correlation should be no less than $0.5 .^{7}$ The lowest value used as reference in clinical studies is $0.7 .^{3,16}$ Thus, the internal consistency was valid, with a global alpha index of 0.72 which is in excess of recommended values in clinical studies. ${ }^{3,16}$ In this paper, the 12 item integrating limitation scale on mandibular functioning presents the same conceptual domain and its items correlate with one another, resulting in a true scale.

With respect to the correlation scores regarding different domains of the RDC/TMD Axis II, the Spearman ranks revealed different psychometric properties for each scale studied, demonstrating that the proposed version of the instrument generally had a positive correlation, indicating that the validated version is really measuring what it was intended to measure. ${ }^{1,16}$

Any evaluation instrument must be reproducible over time, that is, it must reproduce the same 
or similar results between two or more applications for the same patient, provided that his/her clinical status has not changed. ${ }^{2}$ The intraexaminer reliability and reproducibility for the tested-retested instrument, in approximately $30 \%$ of the sample studied, was considered valid.

\section{CONCLUSION}

The process for validating the Portuguese version of the RDC/TMD Axis II Questionnaire fol-

\section{REFERENCES}

1. Bowling A. What things are important in people's lives? A survey of the public's judgements to inform scales of health related quality of life. Soc Sci Med. 1995;41:1447-62.

2. Ciconelli RM, Ferraz MB, Santos W, Meinão I, Quaresma MR. Tradução para a língua portuguesa e validação do questionário genérico de avaliação de qualidade de vida SF-36 (Brasil SF-36). Rev Bras Reumatol. 1999;39(3):14350.

3. Cohen J. A coefficient of agreement for nominal scales. Educ Psychol Measurement. 1960;20:37-46.

4. Dworkin SF, LeResche L. Research diagnostic criteria for temporomandibular disorders: review, criteria, examinations and specifications, critique. J Craniomandib Disord. 1992;6:301-55.

5. Dworkin SF, Sherman J, Mancl L, Ohrbach R, LeResche L, Truelove E. Reliability, validity and clinical utility of the research diagnostic criteria for temporomandibular disorders axis II scales: depression, non-specific physical symptoms, and graded chronic pain. J Orofac Pain. 2002;16(3):20720.

6. Fonseca DM, Bonfante G, Valle Al, Freitas SFT. Diagnóstico pela anamnese da disfunção craniomandibular. RGO. 1994;42(1):23-8.

7. Frankfort-Nachmias C, Nachmias D. Research methods in the social sciences. $4^{\text {th }}$ ed. London: Edward Arnald; 1992.

8. Góes PSA. The prevalence and impact of dental pain in Brazilian schoolchildren and their families [Dissertation]. London: Department of Epidemiology and Public Health, Royal Free and University College Medical School, University College London; 2001.

9. Guillemin F, Bombardier C, Beaton D. Cross-cultural adaptation of health-related quality of life measures: lit- lowed the methodology proposed in the literature and resulted in a reproducible and applicable instrument, valid for the Brazilian population, making possible the inclusion of Brazil in transcultural epidemiological studies on temporomandibular disorders. However, the responsiveness over time of the present version validated for the Portuguese language needs to be evaluated in further clinical and epidemiological studies.

erature review and proposed guidelines. J Clin Epidemiol. 1993;46(12):1417-32.

10. Guyatt GH, Feeny DH, Patrick DL. Measuring healthrelated quality of life. Ann Intern Med. 1993;118:622-9.

11. Kosminsky M, Lucena LBS, Siqueira JTT, Pereira FJ, Góes PSA. Adaptação cultural do questionário "Research diagnostic criteria for temporomandibular disorders: axis II" para o português. J Bras Clin Odontol Integr. 2004;8(43):51-61.

12. McNeill C. Temporomandibular disorders: guidelines for classification, assessment and management. The American Academy of Orofacial Pain. $2^{\text {nd }}$ ed. Chicago: Quintessence; 1993.

13. Mota Falcão D, Ciconelli RM, Ferraz MB. Translation and cultural adaptation of quality of life questionnaires: an evaluation of methodology. J Rheumatol. 2003;30(2):37985.

14. Pehling J, Schiffman E, Look J, Shaefer J, Lenton $P$, Fricton J. Interexaminer reliability and clinical validity of the temporomandibular index: a new outcome measure for temporomandibular disorders. J Orofac Pain. 2002;16(4):296-304.

15. Pereira FJ, Favilla EE, Dworkin SF, Huggins KH. Critérios de diagnóstico para pesquisa das desordens temporomandibulares RDC/TMD. On line 2002 [citado 15 jul 2002]. Disponivel em: http://www.rdc-tmdinternational. $\mathrm{org} /$ translations/frmtranslations.htm.

16. Streiner DL, Norman GR. Health measurement scales. $2^{\text {nd }}$ ed. New York: Oxford Press; 1995.

17. Svensson P. Orofacial musculoskeletal pain. In: Giamberardino MA, editor. Pain 2002 - An updated review: refresher course syllabus. Seattle: IASP Press; 2002. p. 447-58. 